\title{
Síndrome de hiperinfección por Strongyloides stercoralis: diagnóstico por medio de citología de lavado broncoalveolar
}

\author{
Hyperinfection Strongyloides stercoralis: diagnosis by \\ bronchoalveolar lavage cytology
}

Liliana Fernández, MD.(1); Alejandro GonzÁlez, MD. (2); Luz Fernanda SuA, MD., PhDc. ${ }^{(3)}$; Diego VARgAS, MD. ${ }^{(4)}$; CARLOS ANDRÉS MuÑOZ, MD. ${ }^{(5)}$

\section{Resumen}

INTRODUCCIÓN: el Strongyloides stercolaris $(S s)$ es un parásito que causa infecciones severas especialmente en inmunocomprometidos; el síndrome de hiperinfección es una de sus manifestaciones más graves. La detección temprana es vital para instaurar el tratamiento adecuado. En ese sentido, la broncoscopia y la citología del lavado broncoalveolar son herramientas útiles para el diagnóstico precoz.

PACIENTES Y MÉTODOS: revisión retrospectiva de casos de síndrome de hiperinfección por Ss diagnosticados con citología de lavado broncoalveolar en la Fundación Valle del Lili, Cali-Colombia, entre 2004-2012; se encontraron 8 casos, se describen las características demográficas, clínicas, factores de riesgo, hallazgos y desenlaces, y se hace una revisión de la literatura.

RESULTADOS: se hallaron 7 hombres (88\%), 1 mujer (12\%), edad promedio 48 años, 2 con virus de inmunodeficiencia humana (VIH) (22\%), 3 con uso crónico de esteroides (trasplante cardiaco, nefritis lúpica y quimioterapia) (33\%), 2 con desnutrición severa, 2 con virus linfotrópico de células T humanas (HTLV-1) positivo. Ninguno presentó eosinofilia. Todos fueron tratados con ivermectina y antibióticos de amplio espectro para cubrir bacteriemia por gramnegativos ( $33 \%$ tuvieron cultivos positivos). La mortalidad intrahospitalaria fue de $62,5 \%$.

CONCLUSIÓN: en pacientes inmunosuprimidos, el síndrome de hiperinfección es una complicación severa de la infección por (Ss), a pesar del gran compromiso del estado general, su presentación cínica no es específica. Se debe tener un alto índice de sospecha para hacer el diagnóstico e instaurar la terapia precoz. En estos casos, La citología del lavado broncoalveolar es una herramienta útil para la identificación del germen.

Palabras clave: Strongyloidiasis, lavado broncoalveolar, citología, síndrome de hiperinfección.

\section{Abstract}

INTRODUCTION: Strongyloides stercoralis (Ss) is a parasite that causes severe infections, especially in immunocompromised patients; hyperinfection syndrome is one of its most serious manifestations. Early detection is vital for initiating adequate therapy. In this sense, bronchoscopy and bronchoalveolar lavage cytology are useful tools for early diagnosis.

PATIENTS AND METHODS: retrospective review of cases of Ss hyperinfection syndrome diagnosed by bronchoalveolar lavage cytology at the Fundación Valle del Lili, Cali over the period from 2004 to $2012 ; 8$ cases were found; we describe the demographic and clinical characteristics, risk factors, findings, and outcomes, and carry out a review of the literature.

RESULTS: 7 male (88\%) and 1 female (12\%) cases were found, the mean age was 48 years, 2 patients $(22 \%)$ had HIV infection, 3 patients had chronically taken steroids (heart transplant, SLE nephritis, and chemotherapy) (33\%), 2 patients were severely malnourished,
${ }^{(1)}$ Medicina Interna, Neumología y Neumología intervencionista. Línea de Investigación Biomédica en Tórax. Fundación Valle del Lili. Profesora Clínica Asociada, Facultad de Ciencias de la Salud, Universidad Icesi. Cali, Colombia.

${ }^{(2)}$ Medicina Interna, Facultad de Ciencias de la Salud, Universidad Icesi. Cali, Colombia.

${ }^{(3)}$ Anatomía Patológica y Patología Clínica, Departamento de Patología y Medicina de Laboratorio, Patología pulmonar. Ciencias Biomédicas. Línea de investigación Biomédica en Tórax, Fundación Valle del Lili. Profesora Clínica Auxiliar, Facultad de Ciencias de la Salud, Universidad Icesi. Cali, Colombia.

${ }^{(4)}$ Anatomía Patológica y Patología clínica. Departamento de Patología, Universidad del Valle. Cali, Colombia.

${ }^{(5)}$ Médico Rural en Investigación, Centro de Investigaciones Clínicas, Fundación Valle del Lili. Línea de Investigación Biomédica en Tórax, Facultad de Ciencias de la Salud, Universidad Icesi. Cali, Colombia.

Correspondencia: Liliana Fernández $\mathrm{T}$. correos electrónicos: 1fernandez@fcvl.org, lilianafernandeztrujillo@gmail.com

Recibido: 01/08/15. Aceptado: 15/08/15. 
2 patients had positive human T-cell lymphotropic virus (HTLV-1). None of the patients had eosinophilia. All were treated with ivermectin and broad spectrum antibiotics in order to cover Gram-negative bacteremia ( $33 \%$ had positive cultures). In-hospital mortality was $62,5 \%$.

CONCLUSION: hyperinfection syndrome is a severe complication of Ss infection in immunocompromised patients. Despite great deterioration of the patient's general condition, its clinical presentation is not specific. A high index of clinical suspicion is necessary for diagnosis and timely therapy. In these cases, bronchoalveolar lavage cytology is a useful tool form identifying the organism.

Keywords: strongyloidiasis, bronchoalveolar lavage, cytology, hyperinfection syndrome.

\section{Introducción}

La estrongiloidiasis es un infección parasitaria en los seres humanos causada por el Strongyloides stercoralis $(S s)$, un nemátodo intestinal, endémico en regiones tropicales y subtropicales que afecta a más de 30 millones de personas en más de 70 países en desarrollo (1-3). Este parásito, presente en suelos contaminados con excretas humanas, se adquiere cuando las larvas infecciosas (filariformes) penetran la piel, migran por el torrente sanguíneo a los alvéolos pulmonares para alcanzar posteriormente el tracto gastrointestinal luego de ser expectorados y deglutidos (4).

La presentación clínica puede variar de acuerdo con el estado inmunológico del paciente. En inmunocompetentes puede presentarse como una enfermedad aguda leve o cursar como una infección crónica asintomática; mientras que en estados de inmunocompromiso, se favorece el aumento y la migración de larvas infectantes, generándose un síndrome de hiperinfección o una estrongiloidiasis diseminada que puede tener una tasa de mortalidad cercana al 100\% (5).

El uso de fármacos inmunosupresores, principalmente los corticoesteroides (6) en el tratamiento de enfermedades crónicas o en pacientes trasplantados, así como la coinfección por HTLV-1 se han descrito como factores que predisponen al desarrollo de hiperinfección y/o diseminación de la estrongiloidiasis (7).

El diagnóstico puede hacerse por examen directo de materia fecal, con una sensibilidad cercana al $50-92 \%$ cuando se hace por triplicado (8-18). Otros métodos incluyen ensayos serológicos como el ELISA, pruebas de biología molecular como la reacción en cadena de la polimerasa en tiempo real (RT-PCR, su sigla en inglés) y el sistema de inmunoprecipitación luciferasa (LIPS). En el síndrome de hiperinfección y en la estrongiloidiasis diseminada, se pueden encontrar larvas infectantes en otras muestras, tales como líquido cefalorraquídeo, pleural y lavado broncoalveolar( $1,8-9)$, así como en secreción orotraqueal y biopsias de tejido.

El tratamiento de primera línea es la ivermectina, y como alternativa terapéutica se recomienda tiabendazol o albendazol (5). Las dosis y vías de administración varían de acuerdo con el estado de infección, requiriéndose incluso la reducción en la terapia de inmunosupresión en casos de hiperinfección o estrongiloidiasis diseminada (10-12).

A continuación se presentan 8 casos de pacientes inmunosuprimidos procedentes del suroccidente colombiano, hospitalizados en una institución de alta complejidad en la ciudad de Cali-Colombia, entre los años 2004 a 2012; quienes presentaron estrongiloidiasis diseminada cuyo diagnóstico se hizo por medio de lavado broncoalveolar.

\section{Materiales y métodos}

Se revisaron de manera retrospectiva los pacientes con diagnóstico de síndrome de hiperinfección por $S s$ realizado por medio de citología del lavado broncoalveolar, entre 2004 a 2012, en la Fundación Valle del Lili, un Hospital 
Universitario de referencia en Cali-Colombia. Se incluyeron variables demográficas básicas, condiciones de inmunosupresión, manifestaciones clínicas, radiológicas, tratamiento y mortalidad. La información se analizó y presentó como estadística descriptiva.

\section{Caso 1}

Hombre de 23 años de edad, con antecedente de infección por VIH, quien ingresó con cuadro clínico de síntomas respiratorios y gastrointestinales inespecíficos y se le hizo diagnóstico inicial de neumonía no especificada. La radiografía simple de tórax evidenció infiltrados intersticiales bibasales y dada la persistencia de síntomas abdominales se ordenó tomografía axial computarizada (TAC) de abdomen, que mostró tiflitis. Se indicó una fibrobroncoscopia que reportó endobronquitis moderada y el resultado del lavado broncoalveolar reveló larvas de Strongyloides, Pneumocistis jirovecii y Blastoconidias. Se trató con ivermectina $6 \mathrm{mg} / \mathrm{ml}$ oral y tuvo evolución clínica adecuada y mejoría completa.

\section{Caso 2}

Mujer de 16 años de edad, con antecedente de infección por HTLV-1, quien ingresó con cuadro clínico de síntomas gastrointestinales (diarrea intermitente, distención abdominal, dolor tipo cólico) y síntomas constitucionales a estudio. Se indicó TAC abdominal que mostró plastrón apendicular y una radiografía simple de tórax que reportó infiltrados intersticiales. Se realizó una fibrobroncoscopia donde se encontró mucosa pálida sin otras lesiones y en el lavado broncoalveolar se detectaron larvas de $S s$ y Blastoconidias. Se realizó manejo con ivermectina $6 \mathrm{mg} / \mathrm{ml}$ oral. En la hospitalización adicionalmente se hizo diagnóstico de tuberculosis pulmonar y se inició tratamiento acortado supervisado tetraconjugado según esquema. Tuvo evolución adecuada y mejoría clínica.

\section{Caso 3}

Hombre de 77 años de edad, con antecedente de enfermedad pulmonar obstructiva crónica y leucemia linfoide crónica en tratamiento, quien ingresó con cuadro clínico de síntomas respiratorios (tos, disnea, dolor torácico leve) y fiebre de bajo grado; se hizo diagnóstico de neumonía adquirida en la comunidad. En la radiografía simple de tórax se identificaron infiltrados mixtos, intersticiales y broncograma aéreo. La fibrobroncoscopia reportó endobronquitis moderada y el lavado broncoalveolar larvas de $S s$ y Blastoconidias. Se realizó manejo con albendazol, fluconazol, ivermectina y antibióticos pero no se obtuvo mejoría clínica; falleció a causa de falla multiorgánica.

\section{Caso 4}

Hombre de 66 años de edad, con antecedente de infección por HTLV-1 en condiciones de desnutrición severa, quien ingresó con cuadro clínico de síntomas respiratorios discretos, gastrointestinales (diarrea y distención abdominal) y deterioro neurológico. Se realizó TAC abdominal donde se identificaron cambios sugestivos de colitis e inflamación del tercio distal del íleon, en tanto que en la radiografía simple de tórax se encontraron infiltrados micronodulares bilaterales. La fibrobroncoscopia describió endobronquitis leve y el lavado broncoalveolar reveló larvas de Ss. Se realizó manejo con ivermectina y antibióticos pese a lo cual no se obtuvo mejoría clínica; desarrolló sepsis por E. coli y murió a causa de falla multiorgánica.

\section{Caso 5}

Hombre de 42 años de edad, con infección por $\mathrm{VIH}$, en condiciones de desnutrición, quien ingresó con cuadro clínico de síntomas gastrointestinales (diarrea intermitente, dolor abdominal) y neurológicos, con diagnóstico de hipertensión endocraneana que requirió manejo con corticoesteroides. La radiografía simple de tórax evidenció infiltrados intersticiales reticulonodulares extensos. La fibrobroncoscopia mostró endobronquitis y el lavado broncoalveolar larvas de Ss. Se realizó manejo con ivermectina y antibióticos pero no se logró mejoría clínica; tuvo herniación cerebral posterior y falleció.

\section{Caso 6}

Hombre de 60 años de edad, con antecedente de trasplante cardíaco en tratamiento 
inmunosupresor, quien ingresó con cuadro clínico de síntomas respiratorios, tos seca y disnea progresiva hasta el reposo, y gastrointestinales (dolor abdominal difuso intermitente y distención leve). Fue hospitalizado con diagnóstico de infección respiratoria en inmunosuprimido. La radiografía simple de tórax presentó infiltrados mixtos, intersticiales bilaterales, con áreas de condensación; el coprológico reportó larvas de Ss y en la fibrobroncoscopia se describió mucosa pálida con secreción sanguinolenta. En el lavado broncoalveolar se encontraron larvas de Ss. Se trató con ivermectina y antibióticos, sin mejoría clínica. Murió a causa de shock séptico.

\section{Caso 7}

Hombre de 31 años de edad, con antecedente de lupus eritematoso sistémico en tratamiento, quien ingresó con cuadro clínico de síntomas respiratorios (tos seca, disnea y dolor torácico), gastrointestinales (discomfort abdominal y deposiciones diarreicas intermitentes), y sospecha de infección de origen pulmonar e intestinal. La radiografía simple de tórax mostró infiltrados reticulonodulares bilaterales. La fibrobroncoscopia reportó mucosa pálida con secreción sanguinolenta y el lavado broncoalveolar larvas de $S s$. Se documentó, además, bacteriemia por Klebsiella pneumoniae multirresistente en tres hemocultivos. Se realizó manejo con ivermectina y antibióticos, sin mejoría clínica. Falleció a causa de shock séptico.

\section{Caso 8}

Hombre de 67 años de edad, con antecedente de enfermedad pulmonar obstructiva crónica, quien ingresó con cuadro clínico de síntomas neurológicos con diagnóstico de glioblastoma multiforme. Se inició manejo con corticoesteroides y durante la hospitalización presentó síntomas respiratorios (tos seca y disnea). La radiografía simple de tórax mostró infiltrados reticulonodulares bilaterales y derrame pleural. La fibrobroncoscopia reportó endobronquitis leve y el lavado broncoalveolar larvas de $S s$. Se trató con ivermectina y mejoró su cuadro respiratorio.

\section{Resultados}

Durante los años evaluados (2004-2012), se encontraron 8 pacientes con síndrome de hiperinfección y citología de lavado broncoalveolar con presencia de larvas de Ss (figura 1). El sexo predominante fue el masculino ( 7 casos), lo que representa el $88 \%$, y edad promedio de 48 años. Todos tenían compromiso inmunológico previo; 2 tenían VIH (25\%), 3 (33\%) usaban esteroides por diferentes comorbilidades, 2 presentaban desnutrición severa y 2 HTLV-1 positivo. No se documentó eosinofilia en ninguno de los casos (tabla 1).

Los síntomas más frecuentes fueron respiratorios y gastrointestinales; 6 pacientes presentaron falla respiratoria que requirió tratamiento con ventilación mecánica. En las imágenes se apreciaron infiltrados pulmonares bilaterales y áreas de condensación (figura 2); la broncoscopia y el lavado broncoalveolar se hicieron en el contexto del estudio del paciente inmunosuprimido con infiltrados pulmonares nuevos, mientras que en algunos el trabajo diagnóstico incluyó biopsias de tejido como mucosa intestinal o ganglio donde también se detectaron las larvas de Ss (figuras 3 y 4 ).

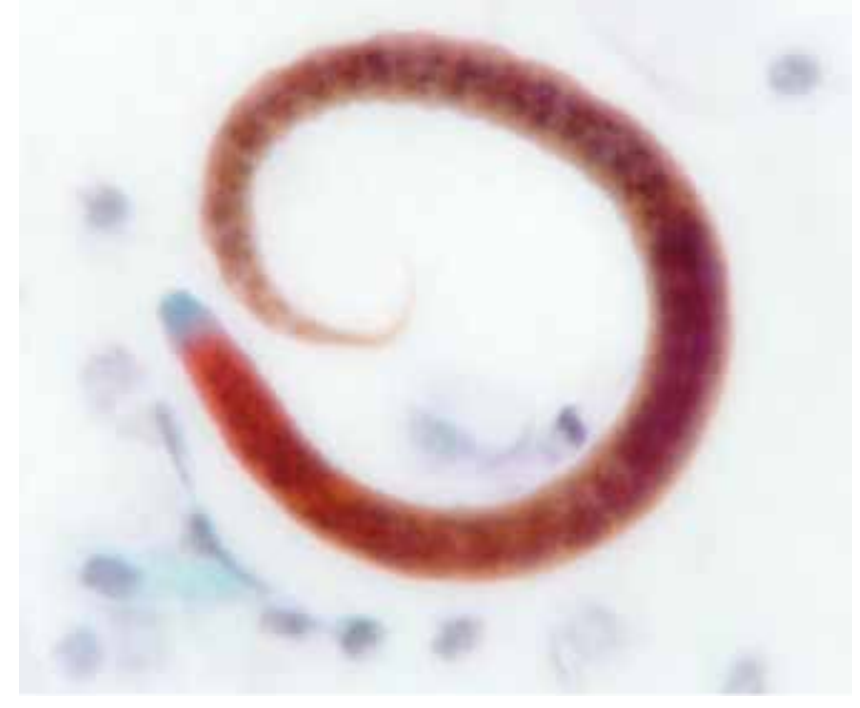

Figura 1. Citología del lavado broncoalvelar. Coloración de Papanicolaou. Se observa la presencia de la larva de Strongyloides stercoralis.

Revista Colombiana de Neumología Vol 27 No 4 | 2015 
Tabla 1. Caracterización de la serie de estudio.

\begin{tabular}{|c|c|c|c|c|c|c|c|c|}
\hline Paciente & 1 & 2 & 3 & 4 & 5 & 6 & 7 & 8 \\
\hline Edad & 23 & 16 & 77 & 66 & 42 & 60 & 31 & 67 \\
\hline Sexo & $M$ & $\mathrm{~F}$ & $M$ & $M$ & $M$ & $M$ & $M$ & $\mathrm{M}$ \\
\hline Procedencia & Urb & Urb & Urb & Urb & Rural & Urb & Rural & Urb \\
\hline Comorbilidades & VIH & HTLV-1 & EPOC, LLC & $\begin{array}{l}\text { HTLV-1, } \\
\text { DNT }\end{array}$ & VIH, DNT & $\begin{array}{l}\text { Trasplante } \\
\text { cardíaco }\end{array}$ & $\begin{array}{l}\text { LES (Ne- } \\
\text { fritis) }\end{array}$ & GM \\
\hline $\begin{array}{l}\text { Tratamiento in- } \\
\text { munosupresor }\end{array}$ & No & No & $\mathrm{Si}$ & No & $\mathrm{Si}$ & $\mathrm{Si}$ & $\mathrm{Si}$ & $\mathrm{Si}$ \\
\hline $\begin{array}{l}\text { Cuadro clínico } \\
\text { de ingreso }\end{array}$ & $\mathrm{R}, \mathrm{GI}, \mathrm{N}$ & $\mathrm{GI}$ & $\mathrm{R}$ & $\mathrm{R}, \mathrm{GI}, \mathrm{N}$ & $\mathrm{GI}, \mathrm{N}$ & $\mathrm{R}, \mathrm{GI}$ & $\mathrm{R}, \mathrm{GI}$ & $\mathrm{R}, \mathrm{N}$ \\
\hline $\begin{array}{l}\text { Diagnóstico de } \\
\text { ingreso }\end{array}$ & Neumonía & $\begin{array}{l}\text { Dolor ab- } \\
\text { dominal a } \\
\text { estudio }\end{array}$ & Neumonía & Neumonía & HEC & Neumonía & $\begin{array}{l}\text { Sepsis } \\
\text { pulmonar } \\
\text { y Gl }\end{array}$ & POP \\
\hline $\begin{array}{l}\text { Infiltrados } \\
\text { pulmonares }\end{array}$ & + & + & + & + & + & + & + & Neumonía \\
\hline $\begin{array}{l}\text { Inflamación } \\
\text { intestinal }\end{array}$ & Tiflitis & $\begin{array}{l}\text { Plastrón } \\
\text { apendicular }\end{array}$ & Sin estudio & $\begin{array}{l}\text { Colitis e } \\
\text { ileitis distal }\end{array}$ & Sin estudio & Sin estudio & $\begin{array}{l}\text { Líquido } \\
\text { y edema } \\
\text { inter-asa }\end{array}$ & + \\
\hline $\begin{array}{l}\text { Leucocitos al } \\
\text { ingreso }\end{array}$ & 3700 & 17200 & 35200 & 9700 & 6320 & 12900 & 9420 & Sin estudio \\
\hline $\begin{array}{l}\text { Eosinófilos al } \\
\text { ingreso No. (\%) }\end{array}$ & $220(5,9)$ & 0 & $100(0)$ & $100(1)$ & 0 & $200(1)$ & 0 & 8410 \\
\hline $\begin{array}{l}\text { Leucocitos (úl- } \\
\text { timo control) }\end{array}$ & 2720 & 10000 & 73200 & 16000 & 7830 & 26200 & 660 & 0 \\
\hline $\begin{array}{l}\text { Eosinófilos al } \\
\text { egreso No. (\%) }\end{array}$ & $130(4,8)$ & 0 & $600(1)$ & $440(3)$ & 0 & 0 & 0 & 8990 \\
\hline Muerte & No & No & $\mathrm{Si}$ & $\mathrm{Si}$ & $\mathrm{Si}$ & $\mathrm{Si}$ & $\mathrm{Si}$ & 3020 (33) \\
\hline $\begin{array}{l}\text { Tiempo desde } \\
\text { hospitalización } \\
\text { al fallecimiento }\end{array}$ & $\mathrm{N} / \mathrm{A}$ & N/A & 4 & 22 & 9 & 55 & 32 & No \\
\hline
\end{tabular}

M: Masculino, F: Femenino, VIH: Virus de Inmunodeficiencia Humana, HTLV-1: Virus Linfotrópico de células T humano Tipo I, EPOC: Enfermedad Pulmonar Obstructiva Crónica, LLC: Leucemia Linfoide Crónica, DNT: Desnutrición, LES: Lupus Eritematoso Sistémico, GM: Glioblastoma Multiforme, R: Respiratorio, GI: Gastrointestinal, N: Neurológico, HEC: Hipertensión Endocraneal, N/A: No Aplica.

\section{Discusión}

El síndrome de hiperinfección por Ss se caracteriza por la aparición o exacerbación de síntomas gastrointestinales y/o pulmonares, producto de la migración acelerada de larvas autoinfectantes. Generalmente se desencadena por alteraciones en el estado inmune de individuos en zonas endémicas con estrongiloidiasis crónica asintomática (1,
$4-5,21)$. De la misma forma, las larvas filariformes pueden migrar a otros órganos fuera del ciclo de autoinfección, tales como hígado, corazón, sistema nervioso central (SNC) y glándulas endocrinas en un proceso que denominado enfermedad diseminada $(12,14)$. En muchos casos el curso de la enfermedad se complica con cuadros de neumonía, meningitis o septicemia por el arrastre 

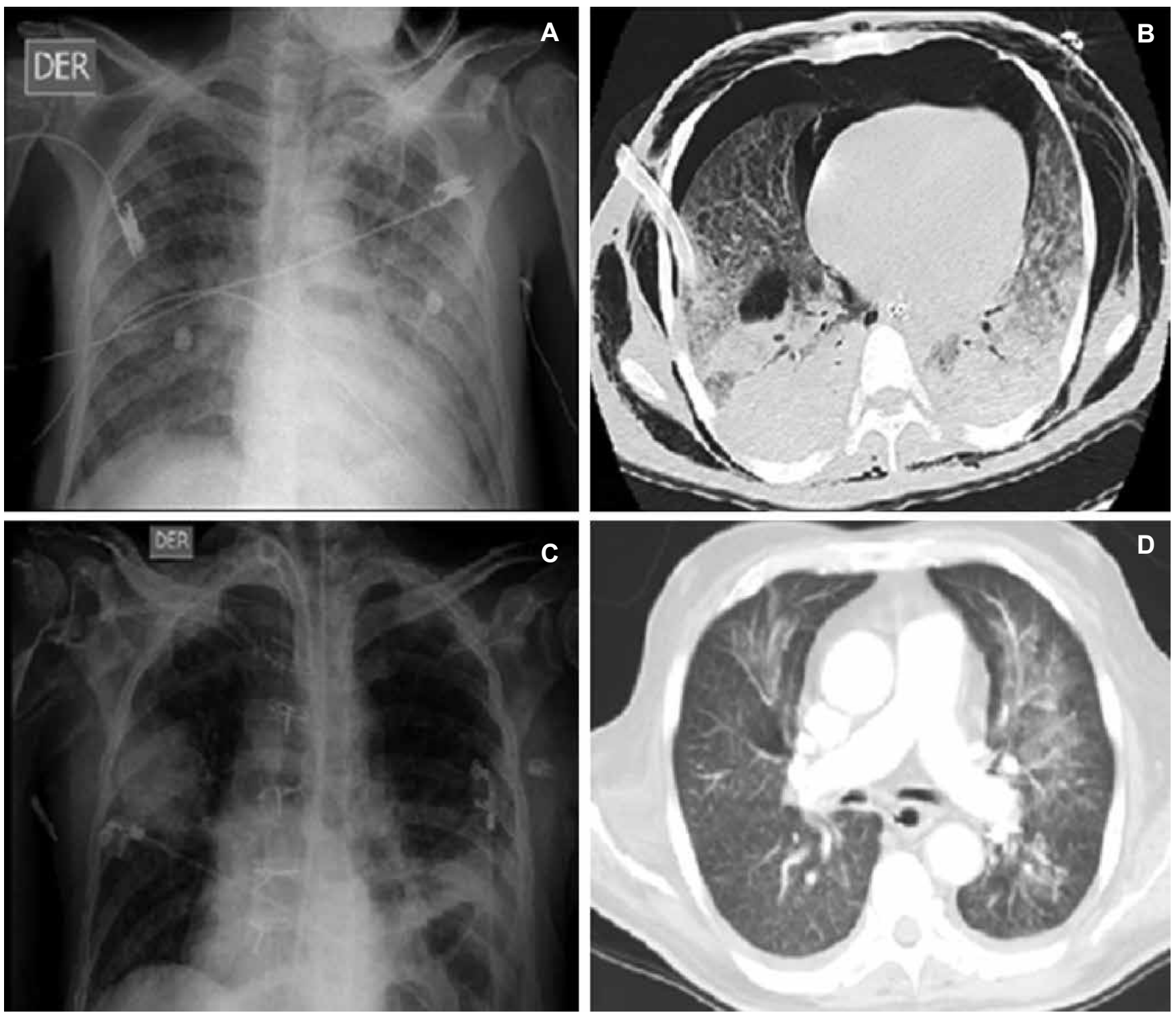

Figura 2. A Infiltrados intersticiales bilaterales diseminados. B TAC de tórax que muestra un neumotórax como complicación durante la ventilación mecánica. C TAC de tórax con infiltrados de ocupación alveolar localizados bilaterales. D. TAC de tórax con infiltrados intersticiales difusos.

de bacterias intestinales gram(-) en el momento de la migración al torrente sanguíneo $(1,5,8,13-$ 14), elevando así la tasa de mortalidad hasta en un $100 \%$ (5). En la serie expuesta, 6 de los pacientes $(75 \%)$ presentaron síntomas respiratorios severos con cambios imagenológicos nuevos en la radiografía de tórax y en 3 de ellos (33\%), que fallecieron, se reportaron cultivos positivos para bacilos $\operatorname{gram}(-)$.
El tratamiento con corticoesteroides constituye el factor de riesgo más frecuente para el desarrollo del síndrome de hiperinfección y/o una enfermedad diseminada $(6,8,16-18)$. La infección sinérgica por HTLV-1 es otro factor de riesgo importante relacionado con la disminución de la acción efectora de la respuesta inmune celular Th2, hecho que favorece la coinfección y migración de las larvas infectantes $(5,7-8,10,19)$. Por otro lado, la presencia de otras 


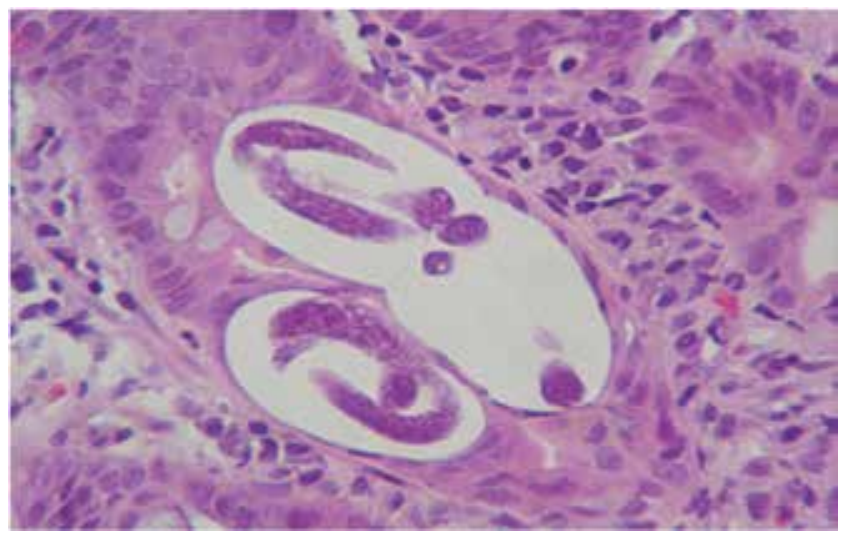

Figura 3. Biopsia de mucosa duodenal con presencia de Strongyloides stercoralis.

condiciones de inmunocompromiso como el alcoholismo, la diabetes, la desnutrición proteico-calórica, el tratamiento para las neoplasias hematolinfoides, el trasplante de órganos sólidos (riñón, hígado, corazón y pulmón) (13), el trasplante de médula ósea, la tuberculosis, la artritis reumatoide, el lupus eritematoso sistémico, la enfermedad inflamatoria intestinal, la EPOC y la sarcoidosis aumentan el riesgo de infección por este nemátodo $(2-5,8,12-14,16-18,21)$.

Así mismo, en esta serie se encontraron múltiples factores de riesgo asociados con el desarrollo del síndrome de hiperinfección por Ss. 5 pacientes $(62,5 \%)$ estaban en tratamiento con esteroides y otros medicamentos inmunosupresores y biológicos para el tratamiento de su enfermedad de base. 2 pacientes $(25 \%)$ sin tratamiento inmunosupresor tenían anticuerpos positivos para HTLV-1, condición asociada con el aumento de IFN- $\gamma$ citoquina, que favorece la diferenciación de linfocitos $\mathrm{T}$ CD4+ a la subpoblación efectora Th1 y disminuye la producción de IL-4, IL-5, IL-13 e IgE, moléculas propias de la subpoblación Th2 esenciales para la defensa del huésped contra los helmintos (7-19).

En Estados Unidos inicialmente las condiciones clínicas más prevalentes relacionadas con la muerte por estrongiloidiasis diseminada fueron la enfermedad pulmonar obstructiva crónica, la infección por VIH y las neoplasias malignas, en especial las de origen hematolinfoide (2). Sin embargo, en la

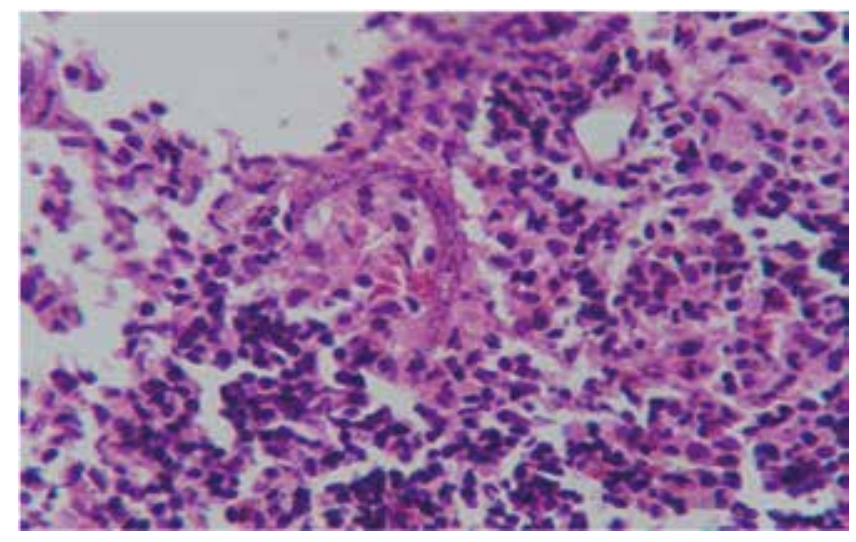

Figura 4. Biopsia de ganglio mesentérico con presencia de Strongyloides stercoralis.

acutalidad la asociación del VIH como un factor de riesgo está en debate $(19,20,22-23)$. Varios reportes consideran que la fuerte relación de la infección diseminada por $S s$ en estos pacientes, se relaciona más con el uso de corticosteroides, el origen geográfico del individuo, donde ambas enfermedades pueden ser frecuentes, y durante el síndrome inflamatorio de reconstitución inmune al inicio de la terapia antirretroviral $(1-2,19)$. Además, se postula que la infección por VIH no altera la respuesta efectora de la subpoblación de linfocitos CD4+ Th2 necesaria para evitar el síndrome de hiperinfección $(7,19)$. Aunque no hay una relación directa con el recuento de linfocitos $\mathrm{T}$ CD4+ para definir un nivel de riesgo en estos pacientes, se ha observado que los niveles bajos de estos linfocitos se asocia más con el aumento de las larvas rabditiformes (no infectivas) y una menor proporción de larvas filariformes (infectivas) $(8,20)$. De los 2 pacientes $\mathrm{VIH}+$, uno tuvo un desenlace fatal sin respuesta al tratamiento antihelmíntico, posiblemente condicionado al estado de inmunocompromiso asociado con otros factores de riesgo como la desnutrición proteico-calórica severa y el uso de corticoesteroides para el control del edema cerebral.

Debido a la gran diversidad de síntomas, muchos de ellos inespecíficos para sospechar la infección parasitaria y a la alta mortalidad asociada, se requiere evaluar con mayor profundidad los casos de pacientes inmunosuprimidos para realizar un diagnóstico precoz, específicamente en 
las zonas endémicas. Los hallazgos radiológicos de estrongiloidiasis pulmonar son muy variables e inespecíficos; pueden estar relacionados con opacidades alveolares difusas, infiltrados intersticiales, derrame pleural, abscesos, SDRA, linfadenopatías mediastínales, consolidaciones o masas sospechosas de malignidad (3-4, 24). En todos los casos $(100 \%)$ se identificaron infiltrados pulmonares de tipo intersticial. Adicionalmente, a los pacientes con síntomas gastrointestinales severos, se les realizaron estudios abdominales con imágenes (TAC o ecografía abdominal), los cuales reportaron hallazgos compatibles con cambios inflamatorios intestinales.

En los casos de estrongiloidiasis crónica asintomática puede haber eosinofilia (eosinófilos igual o mayor a $450 / \mu \mathrm{L})(25)$, sin embargo durante el síndrome de hiperinfección y/o fase diseminada no se presenta, posiblemente debido a la supresión por los corticoesteroides $\mathrm{u}$ otros factores de riesgo como la infección por HTLV-1 (4, 6, 9-10). Por el contrario, la presencia de recuento bajo de eosinófilos, como la leucopenia, se asocia con peor pronóstico (4). En los resultados del hemograma de ingreso, se observó que ninguno de los pacientes $(100 \%)$ presentó eosinofilia. Luego del tratamiento antihelmíntico, 2 pacientes con uso previo de corticoesteroides elevaron el número de eosinófilos a más de $450 / \mu \mathrm{L}$, uno de los cuales falleció. De los 5 pacientes fallecidos solo el paciente con nefritis lúpica tenía reportado recuento bajo de eosinófilos y leucopenia.

El diagnóstico requiere de una alta sospecha clínica, en el que es determinante el hallazgo directo de las larvas filariformes en heces, esputo, lavado broncoalveolar, liquido pleural, ascítico u orina (4-5, 8-9, 17-18). El examen citológico de esputo o de muestras obtenidas por fibrobroncoscopia, como lavado broncoalveolar y cepillado bronquial, se considera una herramienta valiosa para el diagnóstico de la estrongiloidiasis en pacientes inmunosuprimidos en zonas endémicas con síntomas respiratorios progresivos severos de causa no clara (26, 27, 31-32). La preservación de las estructuras larvarias en estas muestras es excelente para visualizar con tinciones tales como: gram, metenamina de plata, Papanicolaou, Diff quik y azul de Prusia (28-30). La identificación de las larvas filariformes para el diagnóstico del síndrome de hiperinfección en nuestra serie de casos, se llevó a cabo en Citología de lavado broncoalveolar. Se usó un proceso citológico convencional para el lavado broncoalveolar según el protocolo estándar del laboratorio de patología de la Fundación Valle del Lili, y se empleó la coloración de Papanicolaou para determinar de manera confiable la identificación morfológica de las larvas de $S s$. Las larvas se reconocen por su forma de gusano, con un extremo delantero grueso y redondeado y una muesca en forma de $\mathrm{V}$ característica al final de la cola puntiaguda (29).

El tratamiento óptimo para las infecciones diseminadas es incierto pero debe ser agresivo, ya que sin este la mortalidad llega al 100\% $(12,13)$. El medicamento de elección es la ivermectina, un antihelmíntico extremadamente potente de amplio espectro introducido para uso animal en 1981 y adaptado para uso humano al rededor de 1988. Es una lactona macrocíclica semisintética derivada de un moho del suelo Stretomyces avermitilis; causa parálisis de muchos parásitos intestinales a través de efectos sobre los canales iónicos de la membrana celular. Se han reportado eventos adversos relacionados con el medicamento pero que no impiden la continuación del tratamiento y eventualmente se asocian más bien a la muerte masiva de parásitos. Este fue el medicamento utilizado en los pacientes de esta serie. La dosis recomendada es de $200 \mathrm{mcg} / \mathrm{kg} /$ día, por vía oral, usualmente por 1 a 2 semanas, hasta lograr negativización de las larvas, con repetición de la dosis 1 a 2 semanas después; como segunda línea de manejo se utiliza el albendazol y la combinación de ambos fármacos $(4-5,8,10,12,15)$. Es importante, además, adicionar antibióticos para cubrir gérmenes gram(-) que causan sepsis por migración desde el tracto gastrointestinal y que contribuyen a la gran mortalidad de este síndrome. Nuestra serie tuvo una mortalidad del $62,5 \%, 5$ de 8 pacientes presentaron un deterioro progresivo de la función de múltiples órganos, hecho que condujo a su fallecimiento pese al tratamiento con ivermectina, albendazol, antibióticos y todas las medidas de manejo para su condición clínica en cuidado intensivo. 


\section{Conclusión}

Los pacientes inmunocomprometidos son una población en riesgo para el desarrollo de infecciones diseminadas por $\mathrm{Ss}$; por tanto, su diagnóstico requiere de una alta sospecha clínica, así como del uso precoz de los métodos disponibles para la identificación de las larvas. La citología del lavado broncoalveolar es una herramienta útil y debe realizarse durante el estudio del paciente endémico inmunosuprimido con síntomas respiratorios progresivos severos asociados a infiltrados pulmonares nuevos; a pesar de estas medidas, la mortalidad sigue siendo alta, incluso con el tratamiento de elección y todas las ayudas de soporte hemodinámico y respiratorio en cuidado intensivo.

\section{Conflicto de intereses}

Los autores declaran no tener conflicto de intereses.

\section{Financiación}

El artículo fue desarrollado con recursos de la Fundación Valle del Lili.

\section{Bibliografía}

1. Siddiqui A.A, Berk S.L. Diagnosis of Strongyloides stercoralis infection. Clinical Infectious Diseases 2001;33:10407.

2. Croker C, Reporter R, Redelings M, Mascola L. Strongyloidiasis-Related Deaths in the United States, 1991-2006. Am. J Trop Med Hyg. 2010;83 422-6.

3. Dogan C, Gayaf M, Ozsoz A, et al. Case report: Pulmonary Strongyloides stercoralis infection. Respiratory Medicine Case Reports 2014;11:12-15.

4. Mokhlesi B, Shulzhenko O, Garimella P.S, Kuma L, Monti C. Pulmonary Strongyloidiasis: The Varied Clinical Presentations. Clin Pulm Med. 2004;11:6.

5. Ramanathan R, Nutman T.B. Strongyloides stercoralis Infection in the Immunocompromised Host. Curr Infect Dis Rep 2008;10:105-10.

6. Yee A, Boylen C.T, Noguchi T, Klatt E.C, Sharma O.P. Fatal Strongyloides stercoralis infection in a patient receiving corticosteroids. West J Med. 1987;146:363-4.

7. Carvalho E.M, Da Fonseca A. Epidemiological and clinical interaction between HTLV-1 and Strongyloides stercoralis. Parasite Immunology 2004;26:487-97.

8. Mejia R, Nutman TB. Screening, prevention, and treatment for hyperinfection syndrome and disseminated infections caused by Strongyloides stercoralis. Curr Opin Infect Dis. 2012;25:458-63.

9. Genta RM, Douce RW, Walzer PD. Diagnostic implications of parasite-specific immune responses in immunocompromised patients with strongyloidiasis. J Clin Microbiol. 1986;23:1099-103.

10. Buonfrate D, Requena A, Angheben A. Severe strongyloidiasis: a systematic review of case reports. BMC Infectious Diseases 2013;13:78.

11. Fusco DN, Downs JA, Satlin MJ, et al. case report: non-oral treatment with ivermectin for disseminated strongyloidiasis. Am J Trop Med Hyg. 2010;83:879-883.

12. Balagopal A, Mills L, Shah A, Subramanian A. Case report: detection and treatment of Strongyloides hyperinfection syndrome following lung transplantation. Transplant Infectious Disease 2009;11:149-54.

13. Roxby AC, Gottlieb GS, Limaye AP. Strongyloidiasis in transplant patients. Clinical Infectious Diseases. 2009;49:1411-23.

14. Ortiz MM, León MD, Muñoz MA, Altuna A, Cano A, Hernández J. Strongyloides stercoralis as an unusual cause of COPD exacerbation. Arch Bronconeumol 2008;44:451-3.

15. Wang C, Xu J, Zhou X. Review: Strongyloidiasis: an emerging infectious disease in China. Am J Trop Med Hyg. 2013;88:420-5.

16. Namisato S, Motomura $\mathrm{K}$, Haranaga $\mathrm{S}$, et al. Pulmonary strongyloidiasis in a patient receiving prednisolone therapy. Int Med. 2004;43:731-6.

17. Tsai MJ, Wu TS, Tsai KB, Chen HC, Hwang JJ, Huang MS. Case report: acute respiratory distress syndrome complicating Strongyloides stercoralis hyperinfection. Int J Gerontol. 2011;5:53-5.

18. Wirk B, W|ngard JR. Case report: Strongyloides stercoralis hyperinfection in hematopoietic stem cell transplantation. Transpl Infect Dis. 2009;11:143-8.

19. Marcos LA, Terashima A, DuPont H.L, Gotuzzo E. Strongyloides hyperinfection syndrome: an emerging global infectious disease. Transactions of the Royal Society of Tropical Medicine and Hygiene. 2008;102:314-8.

20. 11. Villena M.A, Arboleda J.A, Del Arco A, Fernández F. Neumonía grave en paciente con infección por virus de la inmunodeficiencia humana (VIH). Enferm Infecc Microbiol Clin. 2012;30:209-11.

21. Berenson CS, Dobuler KJ, Bia FJ. Fever, petechiae, and pulmonary infiltrates in an immunocompromised peruvian man. The Yale Journal of Biology and Medicine. 1987;60:437-45.

22. Guerin JM, Leibinger F, Mofredj A. Strongyloides stercoralis infection in patients infected with human immunodeficiency virus. Clinical Infectious Diseases. 1997;24:95.

23. Snelling T, Ossowicz C, Boyd M. Case report: co-infections 
in an HIV-infected man from Malawi. Am J Trop Med Hyg. 2007;76:180-1.

24. Kunst H, Mack D, Kon O.M, Banerjee A.K, Chiodini P, Grant A. Parasitic infections of the lung: a guide for the respiratory physician. Thorax. 2011;66:528-36.

25. Pérez J.L, Pardo J, Hernández M, Carranza C, Ángel A, Muro A. Manejo práctico de una eosinofilia. Anales de Medicina Interna. 2004;21:244-52.

26. Williams J, Nunley D, Dralle W, Berk S.L, Verghese A. Diagnosis of pulmonary strongyloidiasis by bronchoalveolar lavage. Chest. 1988;94:643-44.

27. Schainberg L, Scheinberg M. Recovery of Strongyloides stercoralis by bronchoalveolar lavage in a patient with acquired immunodeficlency síndrome. The American Journal of Medicine 1989;87:486.

28. Avant CC, Hitchcock T, Colello CJ, Hoda RS. Strongyloides stercoralis in a bronchoalveolar lavage processed as thinprep. Diagnostic Cytopathology. 2007;35:503-4.

29. Grapsa D, Petrakakou E, Botsoli-Stergiou E, et al. Strongyloides stercoralis in a bronchial washing specimen processed as conventional and thin-prep smears: report of a case and a review of the literature. Diagnostic Cytopathology. 2009;37:903-5.

30. Zhao P, Maleki Z. Strongyloides stercoralis in bronchoalveolar lavage specimen processed as prussian blue stain. Diagn Cytopathol. 2011;0:1-3.

31. Jhala D. Strongyloides hyperinfection diagnosed by bronchoalveolar lavage in an immunocompromized host. Cytopathology. 2010;21:342-51.

32. Cataño JC, Pinzón MA. Images in clinical tropical medicine Strongyloides pneumonia. Am J Trop Med Hyg. 2012;87:195. 